\title{
Design and Realization of Fractional Low-Pass Filter of 1.5 Order Using a Single Operational Transresistance Amplifier
}

\author{
Piyush Kumar Tewari ${ }^{1}$ and Rachana Arya ${ }^{2}$ \\ ${ }^{1}$ P.G student, Bipin Tripathi Kumaon Institute of Technology, Dwarahat, Almora, \\ Uttarakhand \\ ${ }^{2}$ Assistant professor, ECE Deptt, Bipin Tripathi Kumaon Institute of Technology, \\ Dwarahat,Almora,Uttarakhand \\ 1piyushtiwari2877@gmail.com, ${ }^{2}$ rachna009@gmail.com
}

\begin{abstract}
Design of fractional order analog filter, using a single Operational Transresistance Amplifier (OTRA) as an active current mode building block, is presented. The order of the proposed filter is 1.5. The theoretical results have been verified with PSPICE simulation. Obtained filter was realized using OTRA using the RC-RC decomposition technique. Frequency response for the presented filter is shown in the paper. The proposed filter offers some important features: employing single operational transresistance amplifier as an active element, lower sensitivity, insensitive to stray capacitances and parasitic resistances due to internally grounded input terminals of OTRA. Simulation results agree well with the theoretical values.
\end{abstract}

Keywords- Analog filters, fractional order, OTRA, CFE

\section{Introduction}

In mathematics, chaotic character in differentiation and integration was investigated and named as fractional calculus [1-2]. Fractional order systems provide far better results and performance when compared to integer one. Several applications in this field have been developed like fractional order circuit modeling for biomedicine [3], impedance matching networks [4], network traffic modeling [5], Fractional order RF design [6] etc.

Fractional devices can be realized either as ladder, tree, net-grid type or R-C network [7-11] but these circuits have hardware complexity. Fractional devices can also be realized by approximating the fractional order operator by continued fraction expansion (CFE) formula [12].

This paper presents a fractional LPF of order 1.5 using an active current mode analog building block called OTRA i.e., operational transresistance amplifier. RC-RC decomposition technique is used to obtain values of passive components. The paper is structured as follows.

In Section 2, Design of Fractional order low pass filter and RC-RC decomposition technique is presented. In Section 3, implementation of OTRA is given. Finally, in Section 4, simulation results are verified using PSPICE. Section 5 concludes the paper.

\section{Design of Fractional Low Pass Filter of Order 1.5}

\subsection{Continued Fraction Expansion Formula}

Mathematically continued fraction expansion is given by [12]

$$
(1+\mathrm{x})^{\alpha}=\frac{1}{1-} \frac{\mathrm{ax}}{1+} \frac{(1+\alpha) \mathrm{x}}{2+} \frac{(1-\alpha) \mathrm{x}}{3+} \frac{(2+\alpha) \mathrm{x}}{2+} \frac{(2-\alpha) \mathrm{x}}{5+--------}
$$


This expansion converges along the negative real axis from $\mathrm{x}=-\infty$ to $\mathrm{x}=-1$ in the finite complex s-plane. Now to obtain the rational approximation for $\sqrt{\mathrm{s}}, \mathrm{x}=\mathrm{s}-1 \& \alpha=$ 0.5 is substituted and the desired number of terms are taken. Using the Continued Fractional Expansion (CFE) method of [12] the general expression obtained for the second order Laplacian operator is:

$$
\mathrm{s}^{\alpha}=\frac{\mathrm{a}_{0} \mathrm{~s}^{2}+\mathrm{a}_{1} \mathrm{~s}^{1}+\mathrm{a}_{2} \mathrm{~s}}{\mathrm{a}_{2} \mathrm{~s}^{2}+\mathrm{a}_{1} \mathrm{~s}+\mathrm{a}_{0}}
$$

$$
\text { Where } \mathrm{a}_{0}=\alpha^{2}+3 \alpha+2 \quad \mathrm{a}_{1}=8-2 \alpha^{2} \quad \mathrm{a}_{2}=\alpha^{2}+3 \alpha+2
$$

Now using the transfer function of Fractional low pass filter as proposed by [13] and modified by [14-15].

$H_{n+\alpha}^{L P}=\frac{K_{1}}{s^{\alpha}\left(s^{n}+K_{2}\right)+K_{3}}$

Where $\mathrm{n}=$ integer and $0<\alpha<1$ represents a fractional order system and:

$$
\mathrm{K}_{1}=1 \quad \mathrm{~K}_{2}=1.1796 \alpha^{2}+0.167 \alpha^{1}+0.21735 \quad \mathrm{~K}_{3}=0.19295 \alpha^{1}+0.81369
$$

Putting value from (2) in (3) and on further solving, we get:

$\mathrm{H}_{1+\alpha}^{\mathrm{LP}}=\frac{\mathrm{K}_{1}\left(\mathrm{a}_{2} \mathrm{~s}^{2}+\mathrm{a}_{1} \mathrm{~s}+\mathrm{a}_{0}\right)}{\mathrm{a}_{0}\left(\mathrm{~s}^{3}+\mathrm{C}_{0} \mathrm{~s}^{2}+\mathrm{C}_{1} \mathrm{~s}^{1}+\mathrm{C}_{2}\right)}$

Where $\mathrm{C}_{0}=\frac{\left(\mathrm{a}_{1}+\mathrm{a}_{0} \mathrm{~K}_{2}+\mathrm{a}_{2} \mathrm{~K}_{3}\right)}{\mathrm{a}_{0}} \quad \mathrm{C}_{1}=\frac{\left[\mathrm{a}_{1}\left(\mathrm{~K}_{3}+\mathrm{K}_{2}\right)+\mathrm{a}_{2}\right]}{\mathrm{a}_{0}} \quad \mathrm{C}_{2}=\frac{\left(\mathrm{a}_{0} \mathrm{~K}_{3}+\mathrm{a}_{2} \mathrm{~K}_{2}\right)}{\mathrm{a}_{0}}$

For $\alpha=0.5$, i.e., order of the filter $=n+\alpha=1+0.5=1.5$ and the obtained transfer function is:

$$
\mathrm{H}_{1+0.5}^{\mathrm{LP}}=\frac{\left(0.2 \mathrm{~s}^{2}+2 \mathrm{~s}+1\right)}{\left(\mathrm{s}^{3}+2.778083 \mathrm{~s}^{2}+3.21243 \mathrm{~s}^{1}+1.029375\right)}
$$

\subsection{RC-RC Decomposition Technique}

Since the maximum degree is of the denominator $=3$. Thus applying the RC-RC decomposition technique [16-17] the dividing polynomial is of degree $=2$ :

$A(s)=(s+1)(s+2)=s^{2}+3 s+2$

Now dividing the numerator of the obtained transfer function from Equation (4) with A(s), we obtain:

$\frac{\mathrm{N}(\mathrm{s})}{\mathrm{A}(\mathrm{s})}=0.5+\frac{0.8 \mathrm{~s}}{\mathrm{~s}+1}-\frac{1.1 \mathrm{~s}}{\mathrm{~s}+2}$

Let us take: $\quad \mathrm{Y} 1(\mathrm{~s})=0.5+\frac{0.8 \mathrm{~s}}{\mathrm{~s}+1} \quad \& \quad Y 2(\mathrm{~s})=\frac{1.1 \mathrm{~s}}{\mathrm{~s}+2}$

Thus $\quad \frac{\mathrm{N}(\mathrm{s})}{\mathrm{A}(\mathrm{s})}=\mathrm{Y} 1(\mathrm{~s})-\mathrm{Y} 2(\mathrm{~s})$

Applying the same procedure with denominator, we obtain:

$\frac{\mathrm{D}(\mathrm{s})}{\mathrm{A}(\mathrm{s})}=\mathrm{s}+0.51465+\frac{0.4051 \mathrm{~s}}{\mathrm{~s}+1}-\frac{1.4175 \mathrm{~s}}{\mathrm{~s}+2}$ 
Let us take: $\quad \mathrm{Y} 3(\mathrm{~s})=\mathrm{s}+0.51465+\frac{0.4051 \mathrm{~s}}{\mathrm{~s}+1} \quad \& \quad Y 4(\mathrm{~s})=\frac{1.4175 \mathrm{~s}}{\mathrm{~s}+2}$

Thus

$$
\frac{\mathrm{D}(\mathrm{s})}{\mathrm{A}(\mathrm{s})}=\mathrm{Y} 3(\mathrm{~s})-\mathrm{Y} 4(\mathrm{~s})
$$

Thus the entire mathematical approach gives the following decomposition:

$\frac{\mathrm{N}(\mathrm{s}) / \mathrm{A}(\mathrm{s})}{\mathrm{D}(\mathrm{s}) / \mathrm{A}(\mathrm{s})}=\frac{\mathrm{Y} 1(\mathrm{~s})-\mathrm{Y} 2(\mathrm{~s})}{\mathrm{Y} 3(\mathrm{~s})-\mathrm{Y} 4(\mathrm{~s})}$

Where Y1(s), Y2(s), Y3(s) and Y4(s) are positive real admittance functions and thus these can be split into the passive elements combination of $\mathrm{R}$ and $\mathrm{C}$ from where the normalized values of resistances and capacitances can be found.

The values obtained are normalized. To denormalize these proper ZSF (Zero scaling factor) and FSF (Frequency scaling factor) values are used [18-19]. Consider the ZSF = $80 \times 10^{3}$ and $\mathrm{FSF}=2 \pi \times 100 \times 10^{3}$ for the desired $100 \mathrm{kHz}$ cut-off frequency.

To obtain actual values, the multiplication factor is given by: $\mathrm{R}=\mathrm{R}_{\mathrm{n}} \times \mathrm{ZSF}$

$$
\mathrm{C}=\frac{\mathrm{C}_{\mathrm{n}}}{\mathrm{ZSF} \times \mathrm{FSF}}
$$

where $R_{n}$ and $C_{n}$ are the normalized values of resistance and capacitance.

$\mathrm{R}=\mathrm{R}_{\mathrm{n}} \times 80 \mathrm{k} \Omega$

$\mathrm{C}=\mathrm{C}_{\mathrm{n}} \times 19.88636 \mathrm{pF}$

Table 1. Actual Values of Passive Elements

\begin{tabular}{|c|c|c|}
\hline $\begin{array}{c}\text { Resistances } \\
\& \\
\text { Capacitances }\end{array}$ & $\begin{array}{c}\text { Normalized } \\
\text { values }\end{array}$ & $\begin{array}{c}\text { Actual values } \\
\text { (practical } \\
\text { values) }\end{array}$ \\
\hline $\mathrm{R}_{0}$ & $2 \Omega$ & $160 \mathrm{k} \Omega$ \\
\hline $\mathrm{R}_{1}$ & $1.25 \Omega$ & $100 \mathrm{k} \Omega$ \\
\hline $\mathrm{C}_{1}$ & $0.8 \Omega$ & $15.9090 \mathrm{pF}$ \\
\hline $\mathrm{R}_{2}$ & $0.9090 \Omega$ & $72.7272 \mathrm{k} \Omega$ \\
\hline $\mathrm{C}_{2}$ & $0.55 \Omega$ & $10.9374 \mathrm{pF}$ \\
\hline $\mathrm{R}_{3}$ & $1.9430 \Omega$ & $155.445 \mathrm{k} \Omega$ \\
\hline $\mathrm{C}_{3}$ & $1 \Omega$ & $19.8863 \mathrm{pF}$ \\
\hline $\mathrm{R}_{4}$ & $2.4685 \Omega$ & $197.482 \mathrm{k} \Omega$ \\
\hline $\mathrm{C}_{4}$ & $0.4051 \Omega$ & $8.05596 \mathrm{pF}$ \\
\hline $\mathrm{R}_{5}$ & $0.7504 \Omega$ & $56.4373 \mathrm{k} \Omega$ \\
\hline $\mathrm{C}_{5}$ & $0.7085 \Omega$ & $14.0944 \mathrm{pF}$ \\
\hline
\end{tabular}

\section{Realization of Fractional Low-Pass Filter of Order 1.5}

\subsection{OTRA and Its Implementation}

Operational transresistance amplifier (OTRA) has been used as a current mode active block to realize the proposed fractional device. It is current mode analog building block which offers multiple advantages over the traditional voltage mode configurations like higher operating speed, Low power consumption, greater linearity, low voltage operation, 
greater gain-bandwidth product, high CMRR, high slew rate and wider dynamic range [23].

It has two input terminals and one output terminal. The input terminals being at the ground potential make most of the effects of parasitic capacitances and resistances to disappear and thus the proposed circuit is insensitive to stray capacitances.

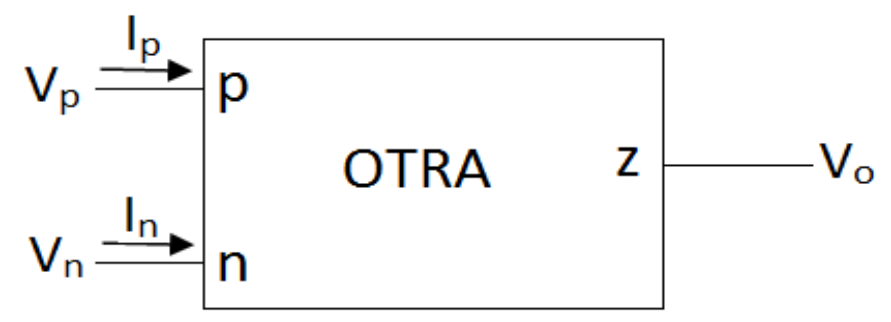

Figure 1. OTRA Block Diagram

Where $V_{p}$ and $V_{n}$ represent corresponding input voltages at terminal $p$ and $n$.

The corresponding port-relationship is characterized as:

$$
\left[\begin{array}{l}
V_{p} \\
V_{n} \\
V_{o}
\end{array}\right]=\left[\begin{array}{ccc}
0 & 0 & 0 \\
0 & 0 & 0 \\
R_{m} & -R_{m} & 0
\end{array}\right]\left[\begin{array}{l}
I_{p} \\
I_{n} \\
I_{0}
\end{array}\right]
$$

This results in:

\section{Port Relationship in OTRA}

$$
V_{p}=0 ; V_{n}=0 ; V_{o}=\left(I_{p}-I_{n}\right) R_{m}
$$

Where $R_{m}$ shows the trans-resistance gain of the OTRA which approaches infinity for ideal operation.

Various implementations of OTRA are available in literature and are based on:

i. Using commercially available AD844 (CFOA) ICs [20].

ii. Using integrated circuit implementations [21-22].

The proposed work has been done using the commercial available IC AD844AN to implement the OTRA. Supply voltages used are $\pm 5 \mathrm{~V}$. Pspice v10.5 has been used to verify the theoretical results.

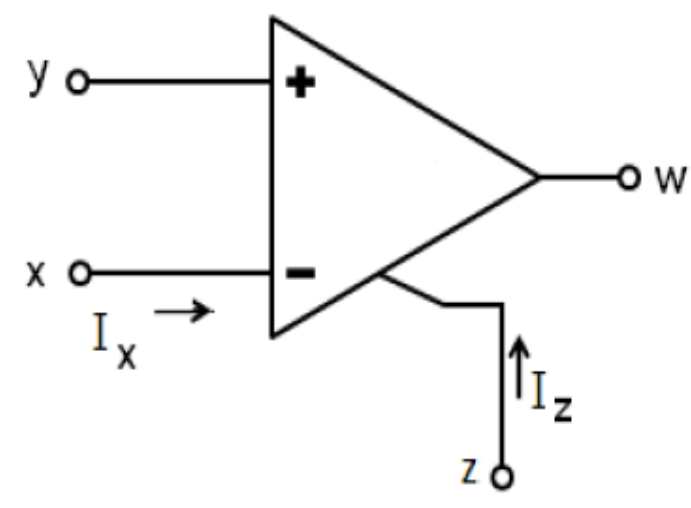

Figure 2. CFOA Circuit Symbol 
The circuit symbol of CFOA is shown in Figure 2 and the port relations of CFOA can be characterized by:

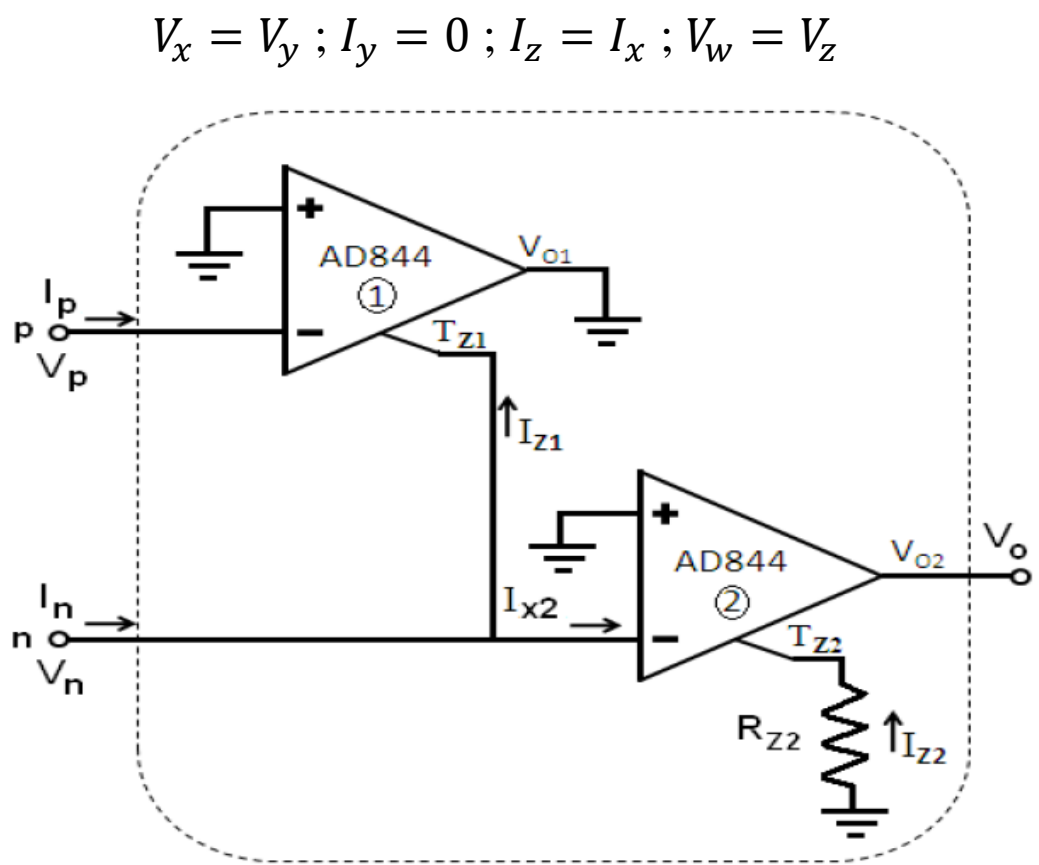

Figure 3. Implementing an OTRA with Two AD844

Figure 3, shows the interconnection of the two AD844 (CFOA) ICs to implement an OTRA block.

From Figure 3, various currents can be calculated as:

$$
\begin{aligned}
\mathrm{I}_{\mathrm{z} 1} & =\mathrm{I}_{\mathrm{p}} \\
\mathrm{I}_{\mathrm{x} 2} & =\mathrm{I}_{\mathrm{n}}-\mathrm{I}_{\mathrm{z} 1} \\
\mathrm{I}_{\mathrm{z} 2} & =\mathrm{I}_{\mathrm{x} 2}
\end{aligned}
$$

From the above equations, the current through $\mathrm{Z}_{2}$ terminal can be computed as $\mathrm{I}_{\mathrm{z} 2}=\mathrm{I}_{\mathrm{n}}-\mathrm{I}_{\mathrm{p}}$

The voltages at various ports are calculated as:

$$
\begin{aligned}
& V_{p}=V_{1-}=V_{1+}=0 \\
& V_{n}=V_{1-}=V_{1+}=0 \\
& V_{o}=V_{z 2}=-I_{z 2} R_{z 2}=\left(I_{p}-I_{n}\right) R_{z 2}
\end{aligned}
$$

Hence $R_{z 2}$ corresponds to the transresistance of OTRA, which is infinite for ideal operation. 


\subsection{OTRA Topology Used for Filter Design}

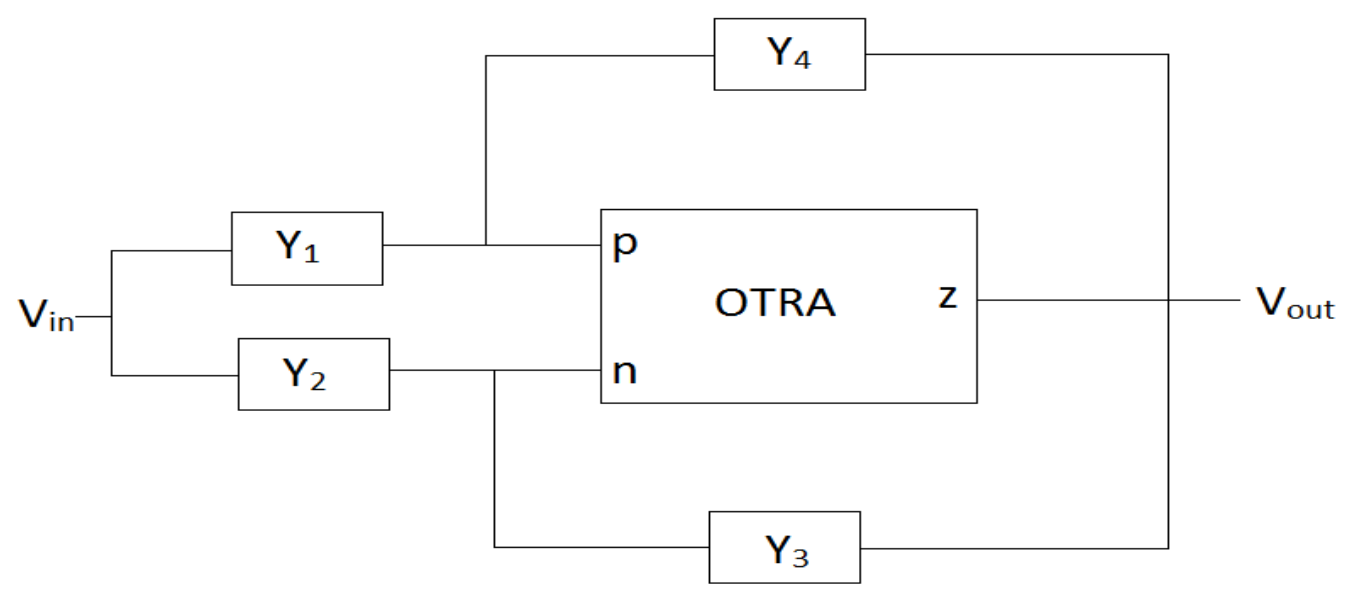

Figure 4. OTRA Topology Used for Realizing the Proposed Filter

Using routine analysis voltage transfer function of the above configuration (Figure 4) of OTRA can be found as:

$$
T F(s)=\frac{\text { Vout }}{\operatorname{Vin}}=\frac{Y 1(s)-Y 2(s)}{Y 3(s)-Y 4(s)}
$$

The above obtained equation can be easily compared to Equation (5) to notice the similarity which was the actual purpose of decomposition of the transfer function. Now thus the admittance values can be replaced by their resistance and capacitance equivalents from the Table 1. The decomposition of the transfer function helped in determining the correct combination of resistance and/or capacitance and then exact values were found by ZSF and FSF. All these when applied to Figure 4 will incorporate the proposed filter structure.

\section{Simulation Results}

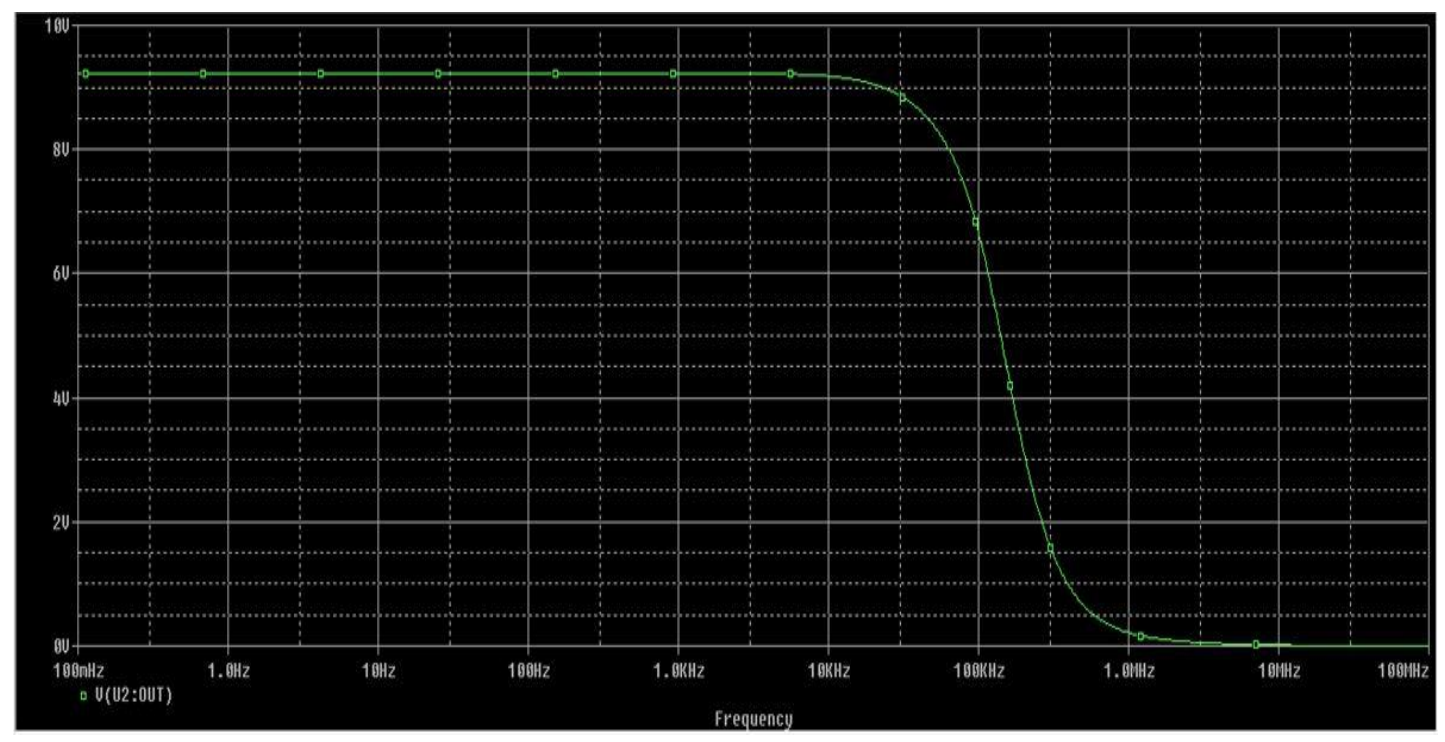

Figure 5. Frequency Response Curve of the Proposed Filter 
The functionality of the proposed fractional order LPF is verified through PSPICE simulation using CFOA based realization of OTRA. The supply voltages for the simulation purpose are $\pm 5 \mathrm{~V}$.

The cut-off frequency obtained from the frequency response curve of fractional LPF through Pspice simulation is: $103.784 \mathrm{~Hz}$. Thus the simulated results are in close harmony with the assumed theoretical value of $100 \mathrm{~Hz}$. The tolerance of the component values may be the reason of the variation in the simulated value. It is also importance to note that the filter circuit functions almost ideally for an ultra wide band of frequency viz. $100 \mathrm{mHz}$ to $100 \mathrm{Mhz}$.

\section{Conclusion}

In this paper, realization of the Fractional LPF of order 1.5 through OTRA is presented. CFE method is utilized to convert the transfer function from the integer order form to the fractional order form. PSpice simulation results are produced to authenticate the efficiency of the proposed design. Although matching for multiple passive components is needed, the proposed filter offers the subsequent benefits: (i) single OTRA is used, (ii) lower output impedance and thus suitable for cascading, (iii) ultra wide freq range of operation, (iv) all the capacitors are grounded or virtually grounded, hence appropriate for fabricating the fractional filter in the monolithic IC form. Due to the proposed device exhibiting LPF behavior for a wide frequency range it can have tremendous application in the field of communication, control system and biomedical. The proposed work gives a direction towards the realization of higher order fractional filters and a hope to fabricate the fractional devices in IC form.

\section{References}

[1] K. B. Oldham and J. Spanier, "The fractional Calculus: Theory and Application of Differentiation and integration to Arbitrary Order", New York,: Academic, (1974).

[2] M. D. Ortigueira, "Fractional Calculus for Scientist and Engineers. Heidelberg", Germany: Springer, (2011).

[3] T. J. Freeborn, "A Survey of Fractional-Order Circuit Models for Biology and Biomedicine", IEEE Journal on Emerging and Selected Topics in Circuits and Systems, vol. 3, no. 3, (2013) September.

[4] A. G. Radwan, A. Shamim and K. N. Salama, "Theory of Fractional Order Element Based Impedance Matching Networks", IEEE Microwave and Wireless Components Letters, vol. 21, no. 3, (2011) March.

[5] V. Zaborovsky and R. Meylanov, "Informational Network Traffic Modal Based on Fractional Calculus", Proceedings of the International Conference Info-tech and Info-net, Beijing,China, vol. 1, (2001), pp. 58-63.

[6] A. G. Radwan, A. Shamim and K. N. Salama, "Mathematics behind the Fractional order Smith Chart", Progress in Electromagnetics Research Symposium proceedings, Suzhou, china, (2011) Sept. 12-16.

[7] A. G. Radwan, A. S. Elawakil and A. M. Soliman, "Fractional-Order Sinesoidal Oscillators: Design Procedure and Practical Examples", IEEE Transactions On Circuits And Systems, vol. 55, no. 7, (2008) August.

[8] P. Yifei, Y. Xiao, L. Ke, Z. Jiliu, Z. Ni, Z.Yi and P. Xiaoxian, "Structing Analog Fractance Circuit for 1/2 Order Fractional Calculus", IEEE, (2005), pp. 1039-1042.

[9] T. J. Freeborn, "A Survey of Fractional-Order Circuit Models for Biology and Biomedicine", IEEE Journal on Emerging and Selected Topics in Circuits and Systems, vol. 3, no. 3, (2013) September.

[10] C. M. Ionescu, "Emerging Tools in Engineering: Fractional Order Ladder Impedance Models for Respiratory and Neural Systems", IEEE Journal on Emerging and Selected Topics in Circuits and Systems, vol. 3, no. 3, (2013) September.

[11] A. A. Stanislavsky, "Twist of fractional oscillation", Physica A, vol. 354, (2005), pp. 101-110.

[12] B. T. Krishna and K. V. V. S. Reddy, "Active and Passive Realization of Fractance device of Order1/2", Hindawi Publishing Corporation, Active and Passive Electronic Components, (2008).

[13] A. Radwan, A. Soliman and A. Elwakil, "First-order filters generalized to the fractional domain", Journal of Circuits, Systems and Computers, 5, 6, 8, 20, 21, 55, .vol. 17, no. 1, (2008), pp. 55-66.

[14] T. Freeborn, B. Maundy and A. Elwakil, "Towards the realization of fractional step filters", in 2010 IEEE International Symposium on Circuits and Systems, (2010), pp. 1037-1040. 10.

[15] B. Maundy, A. Elwakil and T. Freeborn, "On the practical realization of higher-order filters with fractional stepping”, Signal Processing,vol. In press accepted manuscript, (2010). 
[16] K. N. Salama and A. M. Soliman, "Active RC applications of the operational transresistance amplifier", Frequenz, vol. 54, no. 7-8, (2000), pp. 171-176.

[17] H. Y. F. Lam, “Analog and Digital Filters: Design and Realization”, Englewood Cliffs, NJ: PrenticeHall, edt.,(1979).

[18] Active filters theory and design by S.A. Pactitis, crc press, 3rd edition.

[19] Analog electronic filters by Hercules G.Dimopoulos, springer,4th edition.

[20] J. J. Chen, H. W. Tsao and C. C. Chen, "Operational transresistance amplifier using CMOS technology", Electronics Letters, vol. 28, (1992), pp. 2087-2088.

[21] C. Acar and S. Ozoguz, "A new versatile building block: current differencing buffered amplifier", Microelectronics Journal, vol. 30, (1999), pp. 157-160.

[22] K. N. Salama and A. M. Soliman, "CMOS operational transresistance amplifier for analog signal processing applications", Microelectronics Journal, vol. 30, (1999), pp. 235-245.

[23] P. Tewari and L. Garia, "Technological Advancements in Current Conveyors \& their Applications", 1st National Conference on Recent Advances in Sciences \& Technology, vol. 1, (2015), pp. 320-326.

[24] K. C. Smith and A. Sedra, "The Current Conveyor : A new Circuit Building Block", IEEE Proc. Circuits and Systems , vol. 56, (1968), pp. 1368-1369. 